\title{
A JUVENILE METATARSAL OF CF. DASPLETOSAURUS TOROSUS: IMPLICATIONS FOR ONTOGENY IN TYRANNOSAURID THEROPODS
}

\author{
Chan-gyu Yun
}

\author{
Received: 23 December 2020 / Accepted: 4 Marth 2021 / Published online: 14 Marth 2021
}

\begin{abstract}
A well preserved, but isolated metatarsal III of a tyrannosaurid dinosaur, originating probably from the Dinosaur Park Formation of Alberta, Canada, is tentatively referred to Daspletosaurus torosus. The size of the specimen suggests that it likely comes from a large juvenile, since the width of the distal end is about $63 \%$ of that of a much larger individual. The morphology of the specimen supports the recently suggested hypotheses that apomorphies of tyrannosaurid taxa may have developed at young growth stages, and that juveniles of albertosaurines and tyrannosaurines may be easier to distinguish from one another than previously thought. Additionally, the specimen reported here is important in that it provides an addition to the very poor juvenile fossil record of Daspletosaurus.
\end{abstract}

Keywords: Dinosauria, Tyrannosauridae, Daspletosaurus, metatarsal, juvenile

\section{INTRODUCTION}

Ontogenetic dimorphism in tyrannosaurid theropods has been described in substantial detail for several species, supported by the study of isolated cranial elements, complete skulls with different ontogenetic stages, and bonebed assemblages including individuals representing multiple growth stages (e.g., Carr, 1999; Carr \& Williamson, 2004; Carr, 2010; Voris et al., 2019; Carr, 2020; Yun, 2020a, 2020b). So far, ontogenetic studies on tyrannosaurids have focused predominantly on changes of the cranial anatomy (e.g., Carr, 1999; Carr \& Williamson, 2004) and only to a much lesser extent on postcranial changes (e.g., Currie, 1998; Yun, 2020a). Additionally, while there are many publications that describe tyrannosaurid postcrania (e.g., Brochu, 2003; Brusatte et al., 2012; Mallon et al., 2020), phylogenetically or ontogenetically informative variations in tyrannosaurid postcranial elements are still poorly understood (Holtz, 2004; Carr, 2005). Thus, any new data would be significant for clarifying these problems.

It is recognized that two tyrannosaurid species, Gorgosaurus libratus and Daspletosaurus torosus, co-occur in the Dinosaur Park Formation with outcrops in Alberta, Canada (e.g., Carr et al., 2017; Yun, 2020a, 2020b). While these taxa are known from multiple specimens (Carr et al., 2017), differences between juvenile individuals of these two sympatric species remain understudied (Voris et al., 2019). In particular, the postcranial anatomy of Daspletosaurus torosus has been poorly described, and very few juvenile individuals of this taxon have been recovered (Russell, 1970; Voris et al., 2019). In this work, an isolated left third metatarsal (GMNH-PV 435), tentatively identified as a juvenile Daspletosaurus torosus, is described. Its size is similar to those of other tyrannosaurid juveniles of "large stage 1" (Carr, 1999; Carr et al., 2005) yet it already presents a possible autapomorphy of this taxon. Although the material is admittedly fragmentary, its importance for better understanding tyrannosaurid ontogeny, as well as the general rarity of published postcranial osteological descriptions and figures for Daspletosaurus torosus warrant its reporting and description.

\section{Institutional abbreviations}

AMNH, American Museum of Natural History, New York, U.S.A.; CMN, Canadian Museum of Nature, Ottawa, Canada; GMNH-PV, Paleo-Vertebrate Collection of the Gunma Museum of Natural History, Gunma, Japan; LACM, Natural History Museum of Los Angeles County, California, U.S.A.; MOR, Museum of the Rockies, Montana, U.S.A.; ROM, Royal Ontario Museum, Toronto, Canada, TCM, The Children's Museum of Indianapolis, Indiana, U.S.A.; TMP, Royal Tyrrell Museum of Palaeontology, Drumheller, Canada.

\section{PROVENANCE OF THE SPECIMEN}

Specimen GMNH-PV 435 was purchased by the Gunma Museum of Natural History (Japan) from a fossil dealer several decades ago, and only a very brief, simple note about its provenance is available. The only remaining record is written as "Judith River Formation, Red Deer River valley, Drumheller, Alberta, Canada". Historically, the term "Judith River Formation" has been used for Campanian geological units now termed the Oldman and Dinosaur Park formations that are located in southern Alberta (e.g., Eberth \& Hamblin, 1993; Longrich \& Currie, 2009; Fowler, 2017). It is likely that GMNH-PV 435 came from the lower part of the Dinosaur Park Formation rather than from the underlying Oldman Formation for several reasons: (1) the light chocolate brown as well as gray color of the bone closely matches the conditions seen in other dinosaur fossils from this part of the local section (Longrich, 2010; Yun, 2020a; D.H. Tanke and P.J. Currie. pers. 
comm. To C.-G. Yun, 2020); (2) the most richly fossiliferous exposures along the Red Deer River valley belong to the Dinosaur Park Formation (Sullivan, 2003); and (3) the Dinosaur Park Formation is much more extensively exposed and excavated than the Oldman Formation (Longrich, 2008, 2010).

In this case, "Drumheller" is most likely an error or a very vague localization written on the record of origin for this specimen, as there are no exposures of the Dinosaur Park or the Oldman formations in this area. The possibility that GMNH-PV 435 may have been collected from the uppermost Campanian-lower Maastrichtian Horseshoe Canyon Formation that is widely exposed in the Drumheller area (Fowler, 2017) is tentatively rejected here, based on the following reasons: (1) this unit has never been included under the term, or referred to as the, "Judith River Formation" in Alberta (e.g., Eberth \& Hamblin, 1993; Longrich \& Currie, 2009; Fowler, 2017); (2) there are previously known cases of Dinosaur Park Formation fossils (e.g.,TMP 1983.213.1, TMP 1990.2.32) that are vaguely labeled as coming from "Drumheller" (see Royal Tyrrell Museum of Palaeontology online collection, 2020, http://rtmp.emuseum.com/collections); and (3) dinosaur fossils from the Horseshoe Canyon Formation are dark chocolate brown or black in color, which strikingly differ from the condition seen in GMNH-PV 435 (D.H. Tanke and P.J. Currie. pers. comm. to C.-G. Yun, 2020). In summary, the available archive/registry data and the preservation state are all consistently pointing to the lower Dinosaur Park Formation as the most probably place of origin of this isolated element.

\section{GEOLOGICAL SETTING}

Assuming that the previous argumentation placing the origin of GMNH-PV 435 into the Dinosaur Park Formation is correct, a brief geological overview of the formation is presented here. The Dinosaur Park Formation is about $75 \mathrm{~m}$ thick, and its fluvial and floodplain sediments were derived from the erosion of mountain ranges lying to the west, and deposited during the Campanian stage, between 76.9 and 75.8 Ma (Longrich, 2008; Fowler, 2017; Yun, 2020b). Therefore, the Dinosaur Park Formation is middle-late Campanian in age. The formation is composed of layers thick gray sandstones, reddish-brown siltstones and ironstones, greenish-brown claystones, and thin coals (Maganuco, 2004). The paleoenvironment for the lower part of the Dinosaur Park Formation is interpreted as an alluvial plain dominated by winding river systems, while the upper part is considered as being formed in coastal settings (Eberth, 2005). The Dinosaur Park Formation is famous for its rich assemblage of vertebrates, including freshwater chondrichthyans and osteichthyans, mammals, plesiosaurs, turtles, squamates, crocodylians, pterosaurs, and dinosaurs including birds (e.g., Longrich, 2008; Yun, 2020b; Campbell et al., 2021). The high diversity of ectothermic taxa in the formation suggests the climate was warm for the largest part of the year, while the presence of coals and the absence of caliches in the Dinosaur Park Formation imply a high amount of annual rainfall with very rare periods of drought (Eberth, 2005; Longrich, 2010).

\section{MATERIAL AND METHODS}

Due to the lack of funding at the beginning of this project as well as the intervening COVID-19 pandemic, the anatomical study was conducted using a high-quality cast of the original specimen that is housed at the Gunma Museum of Natural History (GMNH-PV 435), cast made based on a 3D scan realized by museum staff member Toshiyuki Kimura. Anatomical comparisons with other derived tyrannosauroids were made through an extensive review of the literature as well as observations of casts, 3D images and photos supplied by other researchers. The anatomical nomenclature used in this study follows Snively et al. (2004), Carr (2005) and Carr et al. (2017).

\section{SYSTEMATIC PALAEONTOLOGY}

Tyrannosauroidea Osborn, 1906

Tyrannosauridae Osborn, 1906

Tyrannosaurinae Osborn, 1906

Daspletosaurini Voris et al., 2020

Daspletosaurus Russell, 1970

cf. Daspletosaurus torosus Russell, 1970

Material: GMNH-PV 435, a nearly complete left metatarsal III lacking its proximal hook-shaped end.

Locality and age: Upper Cretaceous (Campanian) Dinosaur Park Formation, Alberta, Canada.

Comparative description: GMNH-PV 435 is a nearly complete left metatarsal III, which only lacks its proximalmost end (Fig. 1 and Fig. 2). The maximum length of the preserved bone is about $308 \mathrm{~mm}$ as measured on the medial surface, being $62 \mathrm{~mm}$ high dorsoventrally and $65 \mathrm{~mm}$ wide mediolaterally when measured on the distal articular surface; the circumference at the point of the medial deflection of the shaft is $130 \mathrm{~mm}$. The bone clearly exhibits an arctometatarsalian morphology in which the proximal part is "pinched," and a pronounced ridge is present on the proximoventral surface (Fig. 1B and Fig. 2A). Proximally, where the shaft is broken and incomplete, the bone is only $14 \mathrm{~mm}$ wide mediolaterally, and such a highly constricted width continues for about $100 \mathrm{~mm}$ downward from its proximal end. Distally, the shaft strongly expands mediolaterally, so that the width between the medialmost portion of the medial deflection and the lateral margin of the shaft reaches about $48 \mathrm{~mm}$. The medial deflection of the shaft is prominent (Fig. 1A), similar to the degree seen in Albertosaurus (Currie, 1998: Fig. 1; Mallon et al., 2020: Fig. 15; Fig. 3F, G), in large individuals of Gorgosaurus (e.g., Lambe, 1917: Fig. 44A; 

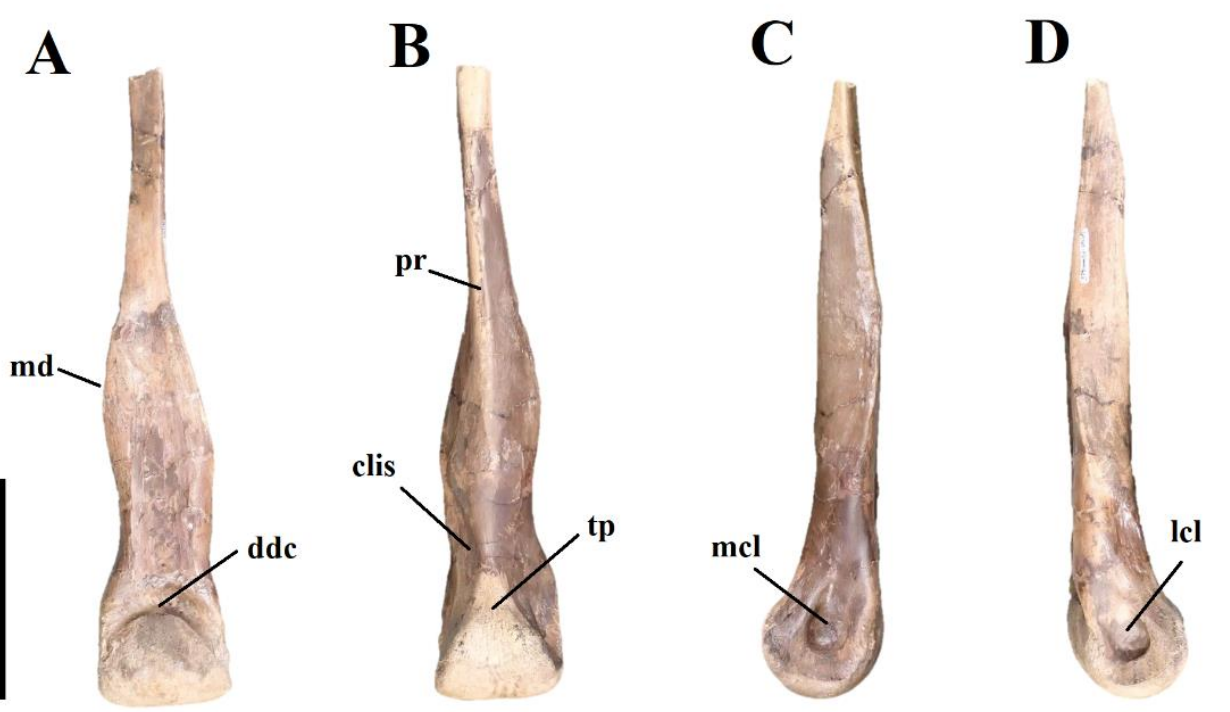

$\mathbf{E}$

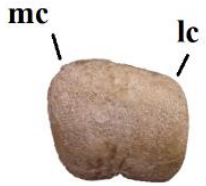

Fig. 1 GMNH-PV 435, a left metatarsal III of cf. Daspletosaurus torosus in A) dorsal view, B) ventral view, C) medial view, D) lateral view, and E) distal view. Abbreviations: clis, caudolateral insertion scar; ddc, dorsal margin of the distal condyle; lc, lateral condyle; lcl, lateral collateral ligament pit; mc, medial condyle; mcl, medial collateral ligament pit; md, medial deflection; pr, proximal ridge of the ventral surface; tp, triangular platform of the ventral surface. Scale bar equals $100 \mathrm{~mm}$.

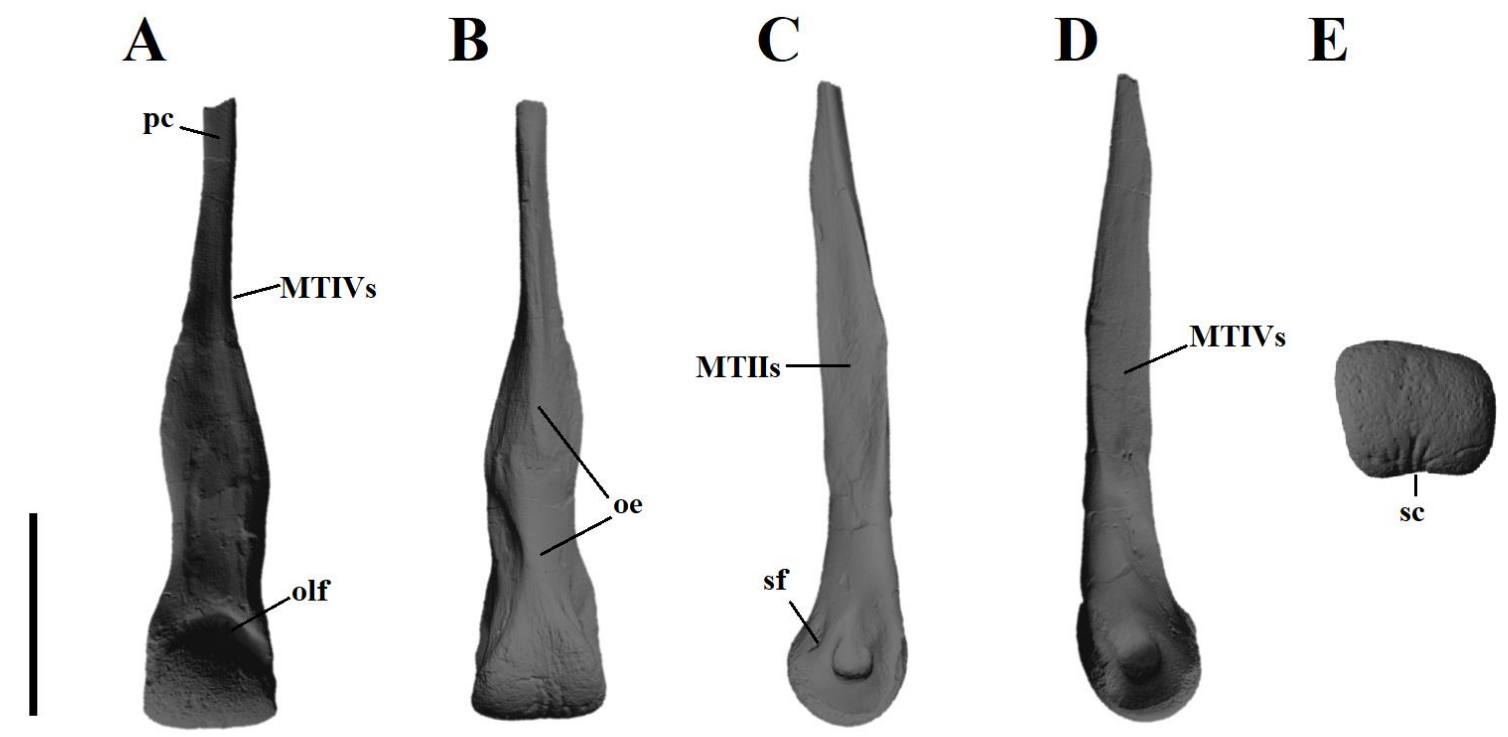

Fig. 2 3D model of GMNH-PV 435 in A) dorsal view, B) ventral view, C) medial view, D) lateral view, and E) distal view. Abbreviations: MTIIs, metatarsal II articulation scar; MTIVs, metatarsal IV articulation scar; oe, oval expansion at the ventral surface; olf, oblique ligament fossa; pc, proximal constriction; sc, sulci between condyles; sf, small foramen ventral to themedial collateral ligament pit. Scale bar equals $100 \mathrm{~mm}$.

Fig. 3C, E), in Daspletosaurus (CMN 350, MOR 590), and in subadult Tyrannosaurus rex (Carr, 2005). In Alectrosaurus, Alioramus, Bistahieversor and juvenile specimens of Gorgosaurus, this feature is more weakly developed (Carr \& Williamson, 2000: Fig. 8L; Carr, 2005; Brusatte et al., 2012: Fig. 78B; Lü et al., 2014: Fig. 3I; Fig. 3D), whereas in adults of Tarbosaurus and Tyrannosaurus rex, this area is very prominent (Brochu, 2003: Fig. 100C; Holtz, 2004; Fig. 3H). The medial margin distal to the deflection is deeply concave, similar to most other derived tyrannosauroids except for Alectrosaurus (Carr, 2005).
The oblique ligament fossa that is immediately proximal to the dorsal margin of the distal condyle is deep, crescentshaped and bears small indentations at its deepest surface (Fig. 2A). Such a deep fossa is common in derived tyrannosauroids, except for Alectrosaurus and Alioramus, which have shallow ones (Carr, 2005; Brusatte et al., 2012: Fig. 78B). The dorsal margin of the distal condyle is convex and slightly medially positioned, as in other derived tyrannosauroids except for Alectrosaurus, which has a nearly horizontal dorsal margin (Carr, 2005).

The distalmost margin of the distal condyle is 
A

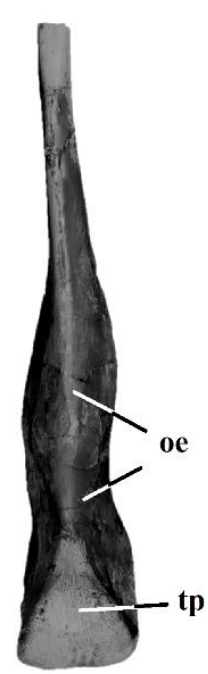

$\mathbf{E}$

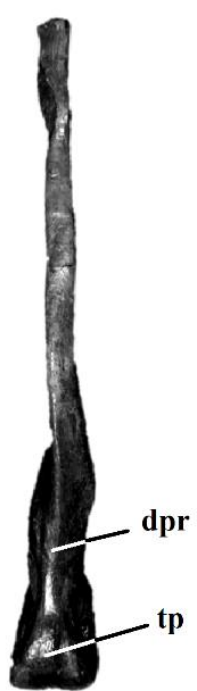

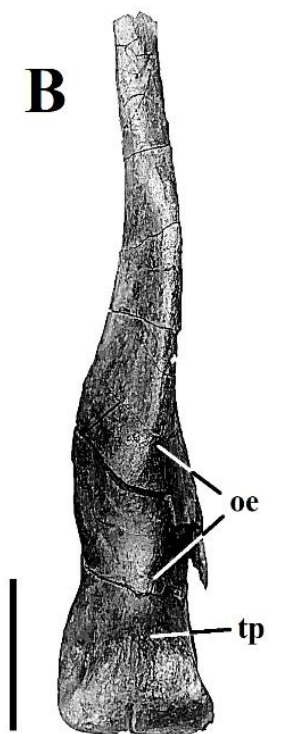

$\mathbf{F}$

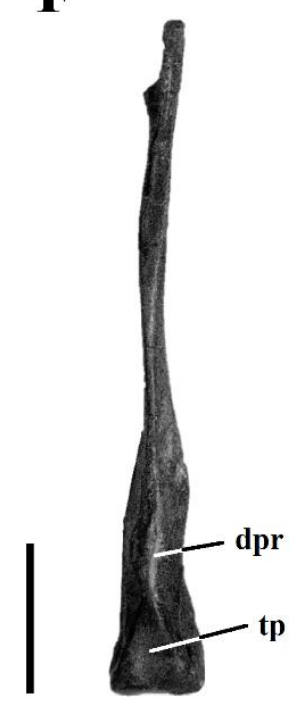

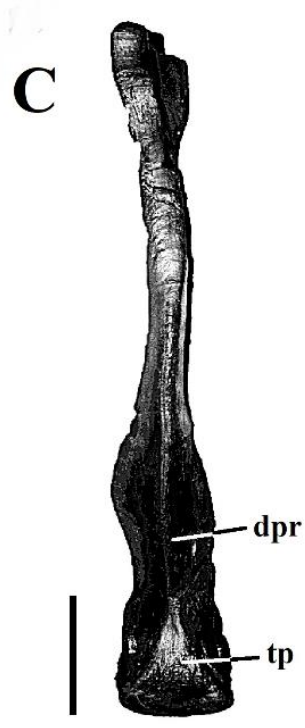

D

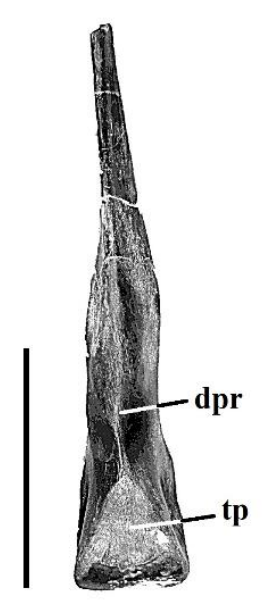

G

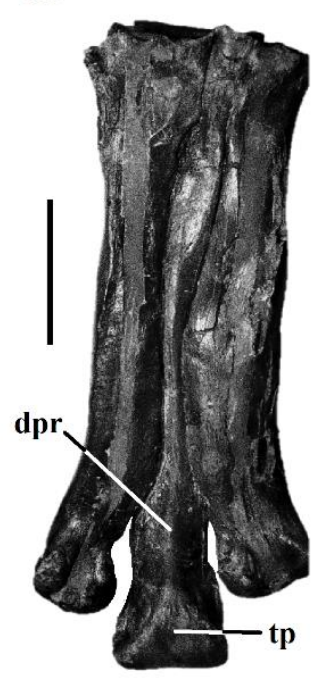

$\mathbf{H}$

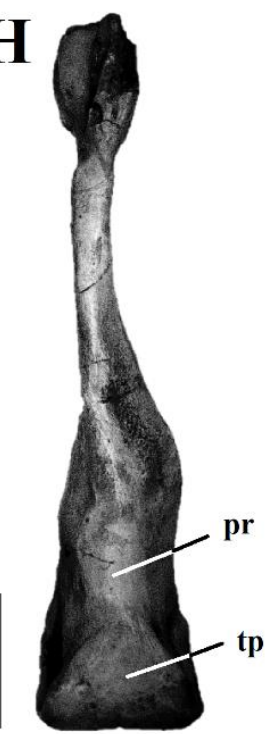

Fig. 3 Illustrations of ventral views of tyrannosaurid metatarsals III. A) GMNH-PV 435, a juvenile cf. Daspletosaurus torosus, B) CMN 350, a large Daspletosaurus torosus, C) TCM 2001.89.1, a large subadult Gorgosaurus libratus, D) TMP 1986.144.1, a small juvenile Gorgosaurus libratus, E) AMNH 5432 (reversed), an adult Gorgosaurus libratus, F) CMN 11315, a juvenile Albertosaurus sarcophagus, G) TMP 81.10.1 (reversed), an adult Albertosaurus sarcophagus, and H) LACM 23844, an adult Tyrannosaurus rex. Photo credits: B - courtesy of Jordan Mallon, C-F - courtesy of Philip Currie, G and H - courtesy of Eric Snively. Abbreviations: dpr, distal pronounced ridge at the ventral surface; oe, oval expansion at the ventral surface; pr, pillarlike thick ridge at the ventral surface; tp, triangular platform of the ventral surface. Scale bar equals $100 \mathrm{~mm}$.

nearly straight in dorsal view (Fig. 1A), as in Daspletosaurus torosus (CMN 350) and in subadult Tyrannosaurus rex (Carr, 2005).

The lateral and medial collateral ligament pits are large, deep, circular in shape, and their dorsal margins are not clearly defined (Fig. 1C, D). This condition differs from the much more shallow, kidney-shaped pits found in Alioramus (Brusatte et al., 2012: Fig. 78C, D) and the proportionally smaller pits present in Tyrannosaurus rex (Brochu, 2003: Fig. 100A, B). A small foramen is present ventral to the medial collateral ligament pit (Fig. 2C), as in some other tyrannosaurid specimens (e.g., AMNH 5432). The lateral and medial surfaces that contact the adjacent metatarsals II and IV are nearly flat, but with some grooves and ridges present as well (Fig. 2C, D).

In the distal part of the ventral surface, there is a raised triangular platform that is positioned immediately proximal to the distal condyles (Fig. 1B), representing one of the key synapomorphies of derived tyrannosauroids (e.g., Lü et al., 2014; Carr et al., 2017). Proximolateral to this platform, there is a deep, teardrop-shaped caudolateral insertion scar (Fig. 1B) similar to the condition reported in 
Appalachiosaurus; it differs in this respect from the shallow conditions present in Alectrosaurus, Bistahieversor and Tarbosaurus (Carr, 2005). In Albertosaurus and Tyrannosaurus rex, both conditions are present (Carr, 2005). An oval-shaped expansion is present immediately proximal to this scar (Fig. 2B); a similar feature can be observed in CMN 350, a Daspletosaurus torosus specimen (Fig. 3B). In Appalachiosaurus, Bistahieversor, Albertosaurus, Gorgosaurus and Daspletosaurus horneri the same region is very constricted and ridge-like (e.g., Carr \& Williamson, 2000: Fig. 8M; Carr et al., 2005: Fig. 19K; E. Snively. pers. comm. to C.-G. Yun, 2020; pers. obs.). In Tarbosaurus and Tyrannosaurus rex, a thick pillar-like structure is present in this area (Brochu, 2003: Fig. 100D; Hattori, 2016: Fig. 5; Fig. 3H). Thus, an oval-shaped expansion on the ventral surface of metatarsal III may represent an autapomorphy of Daspletosaurus torosus (see below). Proximally, a pronounced ridge is present (Fig. 1B).

The distal articular surface is rectangular in shape, and the medial condyle is slightly longer dorsoventrally than the lateral one, as in other tyrannosaurids (Lambe, 1917). The mediolateral width of the surface is larger than the dorsoventral height, similar to most other derived tyrannosauroids. Five broad sulci are present at the ventral part of the articular surface (Fig. 2E).

Taxonomic referral: Since the Dinosaur Park Formation yields two tyrannosaurid taxa, the justification of the tentative referral of this specimen to Daspletosaurus torosus is provided here. The specimen can be confidently assigned to a derived tyrannosauroid (Appalachiosaurus + Tyrannosauridae) and not to any other theropod clade based on the combination of large size, arctometatarsalian condition where the proximal part of metatarsal III is "pinched", the presence of an expansion along the medial edge of the shaft, and the presence of a ventral, triangularshaped non-articular surface that is immediately proximal to the distal condyles (e.g., Holtz, 2004; Carr et al., 2017). Immediately proximal to this triangular platform that is located in the distoventral surfaceof the metatarsal, there is an oval-shaped expansion (Fig. 1B and Fig. 2B). The presence of this structure suggests that this specimen is a Daspletosaurus and not an albertosaurine, since in albertosaurines like Gorgosaurus libratus and Albertosaurus sarcophagus this region is much more constricted and ridgelike along the entire growth series (Fig. 3; E. Snively. pers. comm. to C.-G. Yun, 2020). Indeed, such oval-shaped expansion is also present in CMN 350 (Fig. 3B), a Daspletosaurus torosus specimen (Russell, 1970), whereas during the comparisons, no other derived tyrannosauroid taxon with a similar feature was identified. Based on these observations and the fact that Daspletosaurus torosus and Gorgosaurus libratus are the only valid tyrannosauroids known from the Dinosaur Park Formation until now (e.g., Carr et al., 2017; Yun, 2020a, 2020b), GMNH-PV 435 is tentatively referred to Daspletosaurus torosus. However, it should be emphasized that this referral is provisional since it is based on only one shared character, and the current sample size of pedal elements of Daspletosaurus torosus is low (Russell, 1970; Voris et al., 2020).

\section{DISCUSSIONS}

Implications for tyrannosaurid ontogeny: Specimen GMNH-PV 435, an isolated MT III, is here tentatively referred to Daspletosaurus torosus based primarily on the presence of a distally positioned oval expansion on its ventral surface. The dimensions (e.g., mediolateral width of the distal articular surface) of GMNH-PV 435 are similar to those of ROM 1247, a "large stage 1" juvenile specimen of Gorgosaurus libratus (Carr, 1999; Carr et al., 2005), suggesting a roughly similar body size for the individual represented by the Gunma specimen. Metatarsal III GMNH-PV 435 reaches approximately $63 \%$ of the distal width of the large Daspletosaurus torosus third metatarsal CMN 350 (measurement taken directly from digital photographs supplied by Jordan Mallon). With a body length of about $9 \mathrm{~m}$ assumed for an adult Daspletosaurus (e.g., Russell, 1970; Holtz, 2004), this returns a size of about $5.67 \mathrm{~m}$ for the individual represented by GMNH-PV 435 . Thus, an identification of a large juvenile individual of Daspletosaurus torosus as the source of GMNH-PV 435 is considered to represent the most parsimonious of possibilities.

In its overall morphology, GMNH-PV 435 is quite similar to metatarsals III described and illustrated for many derived tyrannosauroids, and, admittedly, it does not offer much new information on tyrannosaurid postcranial osteology. However, the taxonomic recognition of the specimen has at least several important implications for understanding tyrannosaurid ontogeny, and for the identification of immature individuals. Most importantly, it bears an oval expansion on its ventral surface (Fig. 2B), similar to the condition found in a much larger individual (Fig. 3B) belonging apparently to the same taxon. This suggests that this character - a possible apomorphy of Daspletosaurus torosus - may have already been present in early growth stages of this taxon. Interestingly, the only other Dinosaur Park Formation tyrannosaurid - Gorgosaurus libratus bears a ridge-like constriction in this area of metatarsal III, and this morphology is again conservative across all known growth stages (Fig. 3C, D, E; E. Snively. pers. comm. to C.-G. Yun, 2020). Voris et al. (2019) hypothesized that many tyrannosaurid apomorphies may have developed at young growth stages, and juveniles of tyrannosaurines and albertosaurines could be distinguished from one another easier than previously thought. This hypothesis was already partly supported by Yun (2020a). Now, the identification of the individual represented by GMNH-PV 435 as a juvenile Daspletosaurus torosus and the observations made through this study are also consistent with this hypothesis.

Review of the fossil record of juvenile Daspletosaurus: So far, there are only three definite juvenile specimens of Daspletosaurus reported in the literature: one is an isolated small postorbital from the Dinosaur Park Formation (TMP 
2013.18.11) that probably belongs to Daspletosaurus torosus (Voris et al., 2019), while the other two are a small dentary (MOR 553S/7.19.0.97) and a maxilla from a slightly larger individual (AMNH 5477) of Daspletosaurus horneri (Carr et al., 2017; Delcourt, 2017). Recent work by Voris et al. (2019) demonstrated that a nearly complete juvenile tyrannosaurid skeleton (TMP 1994.143.1) from the Dinosaur Park Formation which has been previously assigned to Daspletosaurus (Currie, 2003), is actually referable to the sympatric Gorgosaurus libratus. This reassessment bears several implications on the current fossil record of juvenile material referred to Daspletosaurus.

Previously, small unserrated tyrannosaurid premaxillary teeth from Upper Cretaceous deposits in North America had been referred to the currently invalid taxon "Aublysodon" (e.g., Carr \& Williamson, 2000; Currie, 2005). However, Currie (2003) asserted that the premaxillary teeth of juvenile Daspletosaurus are unserrated, and Currie (2005) recommended that such unserrated premaxillary tooth from the Dinosaur Provincial Park should be referred to immature Daspletosaurus. This approach was adopted and extended further by several authors, who assigned unserrated tyrannosaurid premaxillary teeth from the contemporaneous Judith River Formation to cf. Daspletosaurus sp. (Dalman \& Lucas, 2015). However, it is now evident that the juvenile Daspletosaurus specimen that Currie (2003, 2005) was referring to is actually specimen TMP 1994.143.1, a fossil which was misidentified at that time (Voris et al., 2019). Thus, the possibility that such teeth might actually represent those of young Gorgosaurus individuals cannot be ruled out, either. However, given that an ontogenetic dimorphism of this feature cannot be verified in Daspletosaurus, a more prudent approach such as identifying all unserrated premaxillary teeth as indeterminate Tyrannosauridae is recommended in this work.

Very recently, Funston et al. (2021) reported an embryonic tyrannosaurid dentary (MOR 268) from the Two Medicine Formation, Montana, and found that it shares several features with juveniles of Alioramus, Gorgosaurus and Daspletosaurus horneri. While these authors have recognized that it lacks several Daspletosaurus horneri autapomorphies (i.e., laterally bowed dentary, anteromedially projecting anterior alveoli, the transition point between the anterior and the ventral margins of the dentary located below the third alveolus), they nevertheless referred the specimen to as cf. Daspletosaurus horneri, mainly based on its stratigraphic and geographic provenance (Carr et al., 2017; Funston et al., 2021). However, Funston et al. (2021) also acknowledged that the shared similarities between MOR 268 and more mature Daspletosaurus horneri specimens are present in Gorgosaurus libratus as well, and definite specimens of Gorgosaurus (e.g. TCM 2001.89.1) are known from the upper Two Medicine Formation where Daspletosaurus horneri is present (e.g., Currie, 2003; Carr et al., 2017; Dalman et al., 2018; P. Larson, pers. comm. to C.-G. Yun, 2019). Additionally, all juveniles of Gorgosaurus lack the aforementioned autapomorphies of
Daspletosaurus horneri that are also absent in MOR 268 (Carr et al., 2017). Lastly, the transition point between the anterior and ventral margins of the dentary MOR 268 is located below the fourth alveolus (Funston et al., 2021), a condition that differs from that reported in Daspletosaurus spp., but which does occur in a similar fashion in several individuals of Gorgosaurus (Brusatte et al., 2012; Dalman and Lucas, 2015; Carr et al., 2017; Voris et al., 2019). Therefore, it is entirely possible that MOR 268 is actually an embryonic Gorgosaurus libratus and does not belong to Daspletosaurus horneri. However, given our obvious lack of detailed knowledge about potential developmental changes between embryonic and juvenile tyrannosaurids, this specimen should best be considered as indeterminate Tyrannosauridae at this time.

Based on these reasons, it is safe to consider only the three cranial elements reported by Carr et al. (2017), Delcourt (2017) and Voris et al. (2019), respectively, to represent definite examples of juvenile Daspletosaurus. Therefore, specimen GMNH-PV 435 is important in that it may represent the fourth known juvenile individual of Daspletosaurus (Carr et al., 2017; Voris et al., 2019), and possibly the first example of a juvenile postcranial element (cf. Voris et al., 2019), as well as in that it documents an individual that is intermediate in size between small juveniles and subadults (Yun, 2020b).

\section{CONCLUSIONS}

A left metatarsal III of a tyrannosaurid theropod, housed in the Gunma Museum of Natural History, is described and identified as a juvenile of cf. Daspletosaurus torosus. This referral was based on the presence of an oval-shaped expansion at its ventral surface, a feature that is seen in a large individual of Daspletosaurus torosus but appears to be absent in other tyrannosaurid species. Therefore, it is possible that this feature represents an autapomorphy of this taxon, though additional investigations on tyrannosaurid metatarsals seem to be necessary to clarify this issue. If the referral of the specimen to Daspletosaurus torosus and the apomorphic nature of the character are correct, these support the recently suggested hypothesis that many tyrannosaurid apomorphies may have developed at young growth stages (Voris et al. 2019). Additionally, this specimen is a possible addition to the scarce fossil record of juvenile Daspletosaurus, which is still largely unknown.

\section{ACKNOWLEDGEMENTS}

The author thanks Yuji Takakuwa and Toshiyuki Kimura (Gunma) for the permission to study the material described in this paper. Darren Tanke (Drumheller), Philip Currie (Edmonton) and Gregory Funston (Edinburgh) are acknowledged for their help in narrowing down the provenance of the specimen. Discussions with Eric Snively (Stillwater) were very helpful to establish the taxonomic identity of the specimen as well. Peter Larson (Hill City) 
is thanked for sharing locality data of TCM 2001.89.1. The author is grateful to Jordan Mallon (Ottawa), Thomas Carr (Kenosha), Eric Snively, Peter Bishop (Brisbane) and Philip Currie for sharing high-resolution pictures and models of various tyrannosaurid specimens used for comparisons. This manuscript benefitted from the comments and suggestions made by the editor (Zoltan Csiki-Sava), and the reviewers Spencer G. Lucas, Claudia Serrano-Brañas and an anonymous reviewer.

\section{REFERENCES}

Brochu, C.A., 2003. Osteology of Tyrannosaurus rex: Insights from a nearly complete skeleton and high-resolution computed tomographic analysis of the skull. Journal of Vertebrate Paleontology, 22(Supplement 4): 1-138.

Brusatte, S.L., Carr, T.D. \& Norell, M.A., 2012. The osteology of Alioramus, a gracile and long-snouted tyrannosaurid (Dinosauria: Theropoda) from the Late Cretaceous of Mongolia. Bulletin of the American Museum of Natural History, 366: 1-197.

Campbell, J.A., Mitchell, M.T., Ryan, M.J. \& Anderson, J.S., 2021. A new elasmosaurid (Sauropterygia: Plesiosauria) from the non-marine to paralic Dinosaur Park Formation of southern Alberta, Canada. PeerJ, 9:e10720.

Carr, T.D., 1999. Craniofacial ontogeny in Tyrannosauridae (Dinosauria, Theropoda).Journal of Vertebrate Paleontology, 19: 497-520.

Carr, T.D., 2005. Phylogeny of Tyrannosauroidea (Dinosauria: Coelurosauria) with special reference to North American forms. Ph.D. thesis, University of Toronto, Ontario, $1170 \mathrm{pp}$.

Carr, T.D., 2010. A taxonomic assessment of the type series of Albertosaurus sarcophagus and the identity of Tyrannosauridae (Dinosauria, Coelurosauria) in the $\mathrm{Al}$ bertosaurus bonebed from the Horseshoe Canyon Formation (Campanian-Maastrichtian, Late Cretaceous). Canadian Journal of Earth Sciences, 47: 1213-1226.

Carr, T.D., 2020. A high-resolution growth series of $T y$ rannosaurus rex obtained from multiple lines of evidence. PeerJ, 8: e9192

Carr, T.D. \& Williamson, T.E., 2000. A review of Tyrannosauridae (Dinosauria, Coelurosauria) from New Mexico. New Mexico Museum of Natural History and Science Bulletin, 17: 113-146.

Carr, T.D. \& Williamson, T.E., 2004. Diversity of late Maastrichtian Tyrannosauridae (Dinosauria: Theropoda) from western North America. Zoological Journal of the Linnean Society, 142: 479-523.

Carr, T.D., Williamson, T.E. \& Schwimmer, D.R., 2005. A new genus and species of tyrannosauroid from the Late Cretaceous (Middle Campanian) Demopolis Formation of Alabama. Journal of Vertebrate Paleontology, 25: 119-143.

Carr, T.D., Varricchio, D.J., Sedlmayr, J.C., Roberts, E.M. \& Moore, J.R., 2017. A new tyrannosaur with evidence for anagenesis and crocodile-like facial sensory system. Scientific Reports, 7: 44942.

Currie, P.J., 1998. Possible evidence of gregarious behavior in tyrannosaurs. Gaia, 15: 271-277.

Currie, P.J., 2003. Cranial anatomy of tyrannosaurid dinosaurs from the Late Cretaceous of Alberta, Canada. Acta Palaeontologica Polonica, 48: 191-226.

Currie, P.J., 2005. Theropods, including birds. In: Currie, P.J., Koppelhus, E.B. (eds.) Dinosaur Provincial Park, a spectacular ancient ecosystem revealed (pp. 367397). Indiana University Press, Bloomington.

Dalman, S.G. \& Lucas, S.G., 2015. New data on the tyrannosaurid theropods from the middle Campanian lower Judith River Formation of north-central Montana. New Mexico Museum of Natural History and Science Bulletin, 67, 77-89.

Dalman, S.G., Lucas, S.G. \& Malinzak, D.E., 2018. Тyrannosaurid teeth from the Upper Cretaceous Two Medicine Formation of Montana. New Mexico $\mathrm{Mu}-$ seum of Natural History and Science Bulletin, 79, 125 139.

Delcourt, R. 2017. A subadult maxilla of a Tyrannosauridae from the Two Medicine Formation, Montana, United States. Papéis Avulsos de Zoologia, 57: 113118.

Eberth, D.A., 2005. The geology. In: Currie, P.J., Koppelhus, E.B. (eds.) Dinosaur Provincial Park, a spectacular ancient ecosystem revealed (pp. 54-82). Indiana University Press, Bloomington.

Eberth, D.A. \& Hamblin, A.P., 1993. Tectonic, stratigraphic, and sedimentologic significance of a regional discontinuity in the upper Judith River Group (Belly River Wedge) of Southern Alberta, Saskatchewan and Northern Montana. Canadian Journal of Earth Sciences, 30: 174-200.

Fowler, D.W., 2017. Revised geochronology, correlation, and dinosaur stratigraphic ranges of the SantonianMaastrichtian (Late Cretaceous) formations of the Western Interior of North America.PLoS ONE,12: e0188426.

Funston, G.F., Powers, M.J., Whitebone, S.A., Brusatte, S.L., Scannella, J.B., Horner, J.R. \& Currie, P.J., 2021. Baby tyrannosaurid bones and teeth from the Late Cretaceous of western North America. Canadian Journal of Earth Sciences (advance online publication).https://doi.org/10.1139/cjes-2020-0169

Hattori, S., 2016. Evolution of the hallux in non-avian theropod dinosaurs. Journal of Vertebrate Paleontology, 36: e1116995.

Holtz, T.R., Jr., 2004. Tyrannosauroidea. In: Weishampel, D.B., Dodson, P. \& Osmólska, H. (eds.) The Dinosauria: Second Edition (pp. 111-136). University of California Press, Berkeley.

Lambe, L.M., 1917. The Cretaceous theropodous dinosaur Gorgosaurus. Canada Department of Mines and Geological Survey Memoir, 100: 1-84.

Longrich, N.R., 2008. A new, large ornithomimid from the Dinosaur Park Formation of Alberta, Canada: 
implications for the study of dissociated dinosaur remains.Palaeontology,51: 983-997.

Longrich, N.R., 2010. Mojoceratops perifania, A New Ceratopsid from the Late Campanian of Western Canada. Journal of Paleontology, 84: 681-694.

Longrich, N.R. \& Currie, P.J., 2009. A microraptorine (Dinosauria-Dromaeosauridae) from the Late Cretaceous of North America. Proceedings of the National Academy of Sciences, 106: 5002-5007.

Lü, J., Yi, L., Brusatte, S.L., Yang, L., Li, H. \& Chen, L., 2014. A new clade of Asian Late Cretaceous longsnouted tyrannosaurids. Nature Communications, 5: 3788.

Maganuco, S., 2004. New dinosaur bones from the Dinosaur Provincial Park (Alberta, Canada) expedition of 1922. Atti della Società italiana di scienze naturali e del Museo civico di storia naturale di Milano, 145: 69-77.

Mallon, J.C., Bura, J.R., Schumann, D. \& Currie, P.J., 2020. A Problematic Tyrannosaurid (Dinosauria: Theropoda) Skeleton and Its Implications for Tyrannosaurid Diversity in the Horseshoe Canyon Formation (Upper Cretaceous) of Alberta. The Anatomical Record, 303: 673-690.

Osborn, H.F., 1906. Tyrannosaurus, Upper Cretaceous carnivorous dinosaur (second communication).Bulletin of the American Museum of Natural History, 22: 281-296.

Royal Tyrrell Museum of Palaeontology, 2020 (accessed year). RTMP Online Collection website, online:http://rtmp.emuseum.com/collections (http://rtmp.emuseum.com/objects/73806/?ctx=047e0d6f-d432-419c-8ab34062ea04bc6d\&idx=0; http://rtmp.emuseum.com/objects/40260/-?ctx=2c3ef10a-0a58-4eab-9fad$55350 \mathrm{cf} 99 \mathrm{e} 5 \mathrm{a} \& \mathrm{idx}=30968$ )
Russell, D.A., 1970. Tyrannosaurs from the Late Cretaceous of Western Canada.National Museum of Natural Sciences, Publications in Paleontology, 1: 1-34.

Snively, E., Russell, A.P. \& Powell, G.L., 2004. Evolutionary morphology of the coelurosaurian arctometatarsus: descriptive, morphometric and phylogenetic approaches. Zoological Journal of the Linnean Society, 142: 525-553.

Sullivan, R.M., 2003. Revision of the dinosaur Stegoceras Lambe (Ornithischia, Pachycephalosauridae). Journal of Vertebrate Paleontology, 23: 181-207.

Voris, J.T., Zelenitsky, D.K., Therrien, F. \& Currie, P.J., 2019. Reassessment of a juvenile Daspletosaurus from the Late Cretaceous of Alberta, Canada with implications for the identification of immature tyrannosaurids. Scientific Reports, 9: 17801.

Voris, J.T., Therrien, F., Zelenitsky, D.K. \& Brown, C.M., 2020. A new tyrannosaurine (Theropoda:Tyrannosauridae) from the Campanian Foremost Formation of Alberta, Canada, provides insight into the evolution and biogeography of tyrannosaurids. Cretaceous Research, 110: 104388 .

Yun, C.-G., 2020a. An exceptionally small juvenile Gorgosaurus libratus (Dinosauria: Theropoda) specimen from the Dinosaur Park Formation (Campanian) of Alberta. The Mosasaur, 11: 107-115.

Yun, C.-G., 2020b. A Subadult Frontal of Daspletosaurus torosus (Theropoda: Tyrannosauridae) from the Late Cretaceous of Alberta, Canada with implications for Tyrannosaurid Ontogeny and Taxonomy. PalArch's Journal of Vertebrate Palaeontology, 17: 1-13. 